strictly compared with cigarette smoking, for oral cavity cancer has been shown to relate to cigar and pipe smoking as well as to tobacco chewing, the former two having a relatively small relationship to lung cancer. What has changed in the last $20-30$ years is not so much the number of tobacco users as the number of cigaretites smoked. Perhaps more pertinent is the fact that the absorption of particulate matter of tobacco smoke for which carcinogenic activity has been demonstrated in animals is significantly greater in the lungs than within the oral cavity of man (page 91).

ERNEST L. WYNDER Dietrich Hoffmann

Sloan-Kettering Institute for Cancer Research, New York.

\section{Not the Mysticism but the Science of Numbers}

SIR,-We have been stimulated, as was no doubt intended, by the recent editorial criticisms (Nature, 217, 793; 1968) of the papers of Professor Derek de Solla Price to reply, for misunderstanding of the trends and objectives of the so-called science of science is evident.

Science is indeed an immaterial cultural product of the intelltcts (and hands) of people but nevertheless has a clear concrete basis in the means of its generation, propagation and use. The situation that in producing science actual people produce actual documents and artefacts, expending real money, time and energy in the process, invites physical measurement. In recent years such measurements have been made with steadily increasing frequency and care.

At the time (1652) when John Graunt, Citizen of London, published his book "Natural and Political Observations ... made upon the Bills of Mortality. With reference to the Government, Religion, Trade, Growth, Ayre, Diseases, and the several Changes of the said City", science was not yet one of the estates of the realm or John Graunt would have examined it. Today, however, the sheer volume of science, or $R \& D$ as it appears in the statistics, is, in terms of people engaged in it, in the USA for example, increasing towards 5 per cent while the proportion engaged in basic agriculture is falling towards 5 per cont. Science, in its material aspects, as a complex devcloping system involving people, information, materials and money, invites study in terms of statistics, cybernetics, systems analysis and other appropriato modern techniques.

This study is required not only "because the object for study is there" and represents an intellectual challenge to the understanding, but because science (if most broadly interpreted) consumes $2-3$ per cent of our GNP and because we believe that the progess of science and of our material prosperity may be interconnected. We similarly believe on statistical grounds that lung cancer and cigarette smoking may be causally related. The relation. ship between science, technology and society can also be discussed in this way, although, of course, as in the biological case, all methods likely to show up the detailed mechanisms must also be tried.

The aim of the science of science is the construction of theoretical foundations for the organization, planning, management and prognosis of science. These foundations must be built from a solid corpus of observations and experiment which will satisfy the critcria of science that they could be repeated by any competent observer who takes the trouble to do so. It is possible that a broad theoretical understanding of the phenomena of science may not result, but it is nevertheless a legitimate hope that on the basis of scientific study the number of variables with which those planning science have to deal may at least be reduced. An experienced gardener gets to know at least some of the conditions essential for the development of his plants. But for what is Professor Price criticized? Mainly for the attempts to introduce quantitative estimates into the study of a human activity. We suspect that the emotional response to this is similar to that greeting the demand for "one man, one vote" which is a crude attempt to quantize politics. At the same time the emotional response to the appearance of "The Double Helix", which shows that science is all too human, indicates that a probe from the opposite dircetion is also striking truth.

We ask the question directly: is it possible to characterize live scientists and real scientific institutions by quantitative indices which summarize information and illuminate key features of the systom?

An attempt to describe the love affair of Romeo and Juliet in numorical terms might appear unpromising, but science is not entirely powerless in this matter. First, the drama (according to Shakespeare at least) has a structure developing in time through the stages: enunciation of the components; development of the conflict; the crisis; the resolution of the crisis and the description of the resulting steady state. Second, science has explicit information even on the processes of love, and poets neglect the findings of molecular biology, of ethology and of communication systems (such as those employing pheromones) at their peril. Studying love is admittedly difficult, but prowess at the intellectual activity of chess is easily quantized and the Grand Masters are found by counting points. Science is surely somewhere in between.

Seience undoubtedly has aspects which can be measured statistically or modelled as systems and, if we do not try to measure them, then someone else will. We must point out that some hundreds of people are now engaged in activities on these lines, so that Price is not alone.

No one may know in advance the day of death of an editor of Nature but, following Graunt, the operation of insurance companies is based on the experimental measurement of the probability of just such occurrences.

The interesting preliminary correlations found by Price indicate that, as in tho case of lung cancer, there is something worth detailed study.

We try to use statistics with responsibility. We find, for example, that in a sequence of $\mathbf{5 3}$ kings a run of four dying on the same day of the week is to be expected with a probability of 1 in 7 so that we do not need to attribute the deaths of the Georges to the malignity of Saturday. The genetics of porphyria has much more relevance.

Similarly in the study of science itself, statistics indicate that there may be things to be explained by detailed study of the actual mechanisms. Here, the work of the estab. lished historians of science, if they can be persuaded to bring their studies up to the science of the present day, provides the basic facts.

Needless to say, as in all branches of science, the science of science can only advance (in the way in which John Ziman describes in "Public knowledge") by the growth of a corpus of knowledge which after criticism is accepted by the scientific community. We think that alrcady in the science of science there is a coherent body of accepted fact enough to define it as a respectable field of study. In this stage editorial blasts will not blow it away; new observations and alternative theories based on the existing facts are needed to disturb the structure which Professor Price has begun to set up.

Gennadi Dobrov

Science of Science Research Division,

Institute of Mathematics,

Academy of Sciences of the Ukr. SSR,

Kiev.

Department of Crystallography,

Alan Mackay

Birkbeck College,

Malet Street,

London, WC1. 